\title{
Biotopical distribution and seasonal activity of model species of the family Gnaphosidae (Araneae) in Zemen gorge (SW Bulgaria)
}

\author{
Christo DELTSHEV \& Gergin BLAGOEV
}

\begin{abstract}
A faunistic study was carried out for three years in Zemen gorge (1984-1986). With the help of BARBER-traps 675 gnaphosid spiders were caught in 4 localities, each with 2 habitats, meadow and forest. 23 species were found in total and their biotopical distribution was recorded. The investigated habitats are faunistically similar, mainly in qualitative respect. In addition data about the phenology of the most frequent species are presented. The males are most abundant in spring and summer and disappear in VIII, the females are most numerous after $\mathrm{VII}$ and can be found till the end of IX, whereas the juveniles can be found till the end of $X$. The species abundance reaches its peak in V-VI.
\end{abstract}

Key words: Gnaphosidae, biotopical distribution, seasonal activity

\section{INTRODUCTION}

The first information on spiders inhabiting the territory of Zemen gorge are given by BLAGOEV \& DELTSHEV (1989) and DELTSHEV \& BLAGOEV (1992). In these publications, all families are discussed in faunistic respect, while the family Lycosidae is reviewed in ecological respect. The present investigation contains new faunistic and ecological data on biotopical distribution of the species of Gnaphosidae, as well as the seasonal activity of the dominant species.

\section{STUDY AREA AND METHODS}

The Zemen gorge is situated in Southwestern Bulgaria and forms a part of the Strouma valley $(22 \mathrm{~km})$ between Konyavska and the Zemen mountains (BLAGOEV \& DELTSHEV 1989, DELTSHEV \& BLAGOEV 1992). The climate is continental, with mediterranean influences in the lower parts; the temperature is higher than in neighbouring districts (TISHKOV 1982). Four 
localities (1,2: near the town Zemen; 3,4: near the villages Skakavitsa resp. Ruzhdavitsa) were examined, each with 2 habitats: meadow and forest (indicated as $\mathrm{H} 1$ and $\mathrm{H} 2$ ). These habitats are characterized as follows:

- H1: Humid, non-managed meadows without shrubs, situated near the river (500 $\mathrm{m}$ a.s.I.). The dominating plant species are Poa pratensis L., Lolium perenne L., Dactylis glomerata L., Arrhenatherum elatius L., Chrysopogon gryllus L., Medicago falcata L., and Trifolium sp..

- H2: Humid mixed forest dominated by decidous trees and bushes such as Salix alba L., Carpinus orientalis L., Corylus avellana L., Prunus divaricata L., Alnus glutinosa L., Crataegus monogyna JACQ.. The underbrush is formed by Quercus cerrus L., Q. pubescens WILLD., Fraxinus orientalis L., Cornus mas L., C. sanguinea L., Syringa vulgarisL., Juniperus oxycedrus $L$.. The grass species are scanty. The forest floor is characterized by a modest layer of leaf litter.

The spider material was collected mainly by BARBER-traps. At each study site, twelve traps were placed in 3 lines, about 5 meters apart from each other. The traps were set during 1984(V-X), 1985(III-X), 1986(III-X) and were emptied once a month. Quantitative faunistic similarity was determined by CZEKANOVSKY-SOERENSEN.

\section{RESULTS AND DISCUSSION}

\section{Species composition}

The spider material contained 675 identifiable specimens. A total of 23 species from 7 genera of the family Gnaphosidae was found in the study area (Tab. 1). All species are new for the region and 4 (Gnaphosa rhenana, Haplodrassus silvestris, Zelotes electus, $Z$. exiguus) are new for the Bulgarian spider fauna (DELTSHEV \& BLAGOEV 1992). The number of species is comparatively high (considering the restricted and monotone region) and represents $33.8 \%$ of the Bulgarian gnaphosid spiders. The genus with the highest species number is Zelotes $(S=11)$. With respect to the abundance of specimens, the most numerous in both habitats are: Haplodrassus signifer $(\mathrm{H} 1-119, \mathrm{H} 2-6)$, Callilepis schuszteri $(\mathrm{H} 1-29, \mathrm{H} 2-56)$, Micaria fulgens ( $\mathrm{H} 1-54, \mathrm{H} 2-31)$ and Zelotes pedestris $(\mathrm{H} 1-73, \mathrm{H} 2-8)$. The number of common species inhabiting both habitats is 11 , which lead to a high SOERENSEN index of faunistic similarity (64.7\%). 
Tab.1 Check list of the gnaphosid spiders (males - $m$, females - $f$ ) established in meadow $(\mathrm{H} 1)$ and forest $(\mathrm{H} 2)$ habitats in Zemen gorge

\begin{tabular}{|c|c|c|c|c|c|}
\hline \multirow{2}{*}{ Species } & \multicolumn{2}{|c|}{$\mathrm{H} 1$} & \multicolumn{2}{|c|}{$\mathrm{H} 2$} & \multirow[t]{2}{*}{$\Sigma$} \\
\hline & $\mathrm{m}$ & f & $\mathrm{m}$ & f & \\
\hline Callilepis nocturna (LINNÉ, 1758) & 27 & 3 & 0 & 0 & 30 \\
\hline Callilepis schuszteri (HERMAN, 1879) & 12 & 17 & 40 & 16 & 85 \\
\hline Drassodes lapidosus (WALCKENAER, 1802) & 5 & 0 & 2 & 1 & 8 \\
\hline Drassodes pubescens (THORELL, 1856) & 7 & 2 & 1 & 1 & 11 \\
\hline Gnaphosa lucifuga (WALCKENAER, 1802) & 0 & 0 & 2 & 0 & 2 \\
\hline Gnaphosa menanaMÜLLER \& SCHENKEL, 1892 & 0 & 0 & 0 & 1 & 1 \\
\hline Haplodrassus signifer (C.L.KOCH, 1839) & 96 & 23 & 4 & 2 & 125 \\
\hline Haplodrassus silvestris (BLACKWALL, 1833) & 5 & 3 & 5 & 4 & 17 \\
\hline Micaria formicaria (SUNDEVALL, 1831) & 2 & 7 & 0 & 0 & 9 \\
\hline Micaria fulgens (WALCKENAER, 1802) & 27 & 27 & 19 & 12 & 85 \\
\hline Micaria pulicaria (SUNDEVALL, 1831) & 10 & 7 & 0 & 0 & 17 \\
\hline Nomisia exornata (C.L.KOCH, 1839) & 2 & 0 & 0 & 0 & 2 \\
\hline Zelotes apricorum (L.KOCH, 1876) & 2 & 0 & 6 & 2 & 10 \\
\hline Zelotes electus (C.L.KOCH, 1839) & 13 & 12 & 0 & 0 & 25 \\
\hline Zelotes erebeus (THORELL, 1870) & 15 & 1 & 18 & 13 & 47 \\
\hline Zelotes exiguus (MÜLLER \& SCHENKEL, 1895) & 12 & 2 & 0 & 0 & 14 \\
\hline Zelotes hermani (CHYZER, 1878) & 18 & 3 & 0 & 0 & 21 \\
\hline Zelotes latreillei(SIMON, 1878) & 0 & 0 & 1 & 0 & 1 \\
\hline Zelotes oblongus (C.L.KOCH, 1839) & 0 & 0 & 5 & 1 & 6 \\
\hline Zelotes pedestris (C.L.KOCH, 1837) & 48 & 25 & 6 & 2 & 81 \\
\hline Zelotes praeficus (L.KOCH, 1866) & 28 & 20 & 0 & 0 & 48 \\
\hline Zelotes pusillus (C.L.KOCH, 1833) & 10 & 0 & 0 & 0 & 10 \\
\hline Zelotes villicus (THORELL, 1875) & 8 & 0 & 7 & 5 & 20 \\
\hline Total & 348 & 152 & 116 & 59 & 675 \\
\hline
\end{tabular}

\section{Biotopic analysis}

From the established 23 species of gnaphosid spiders, 10 are constant species (presence above $50 \%$ ): H. signifer, H. pubescens (75\%), Z. pedestris (62.5\%), D. lapidosus, $H$. silvestris, $M$. fulgens, $Z$. apricorum, $Z$. erebeus, $Z$. praeficus, $Z$. villicus (50\%), 4 are attendants (presence from $25 \%$ till $50 \%$ ): C. schuszteri, Z.hermani(37.5\%), M. pulicaria, Z. pusillus (25\%) and 9species are accidentals: C. nocturna, G. Iucifuga, G. rhenana, M. formicaria, $N$. exornata, $Z$. electus, $Z$. exiguus, $Z$. latreillei, $Z$. oblongus. The distribution of the species in the different habitats is: $43.5 \%$ in the meadows and the forests, $39.1 \%$ in the meadows only and $17.4 \%$ in the forests only. Seven groups of faunistic similarity are established, devided into 2 complexes (Fig. 1). The first complex comprises meadow and forest habitats of the localities 1 and 2 (Zemen) and the second complex comprises meadow 
habitats of the localities 3 and 4 (Skakavitsa, Ruzhdavitsa). The highest similarity is established in the first complex for the two xerotherm forests of the localities 1 and 2. Similar are the data concerning the meadow habitats of the same localities (1: $60 \%, 2: 45 \%)$. In the second complex the highest similarity is established again for the forest habitats of the localities 3 and $4(65 \%)$. Probably this phenomenon can be explained by the similar ecological conditions of the localities examined. In the first complex the meadow and the forest habitats are situated on the humid banks of the river with southern exposition and some xerothermic places. In the second complex these habitats are situated on the humid banks with northern exposition without xerothermic components.

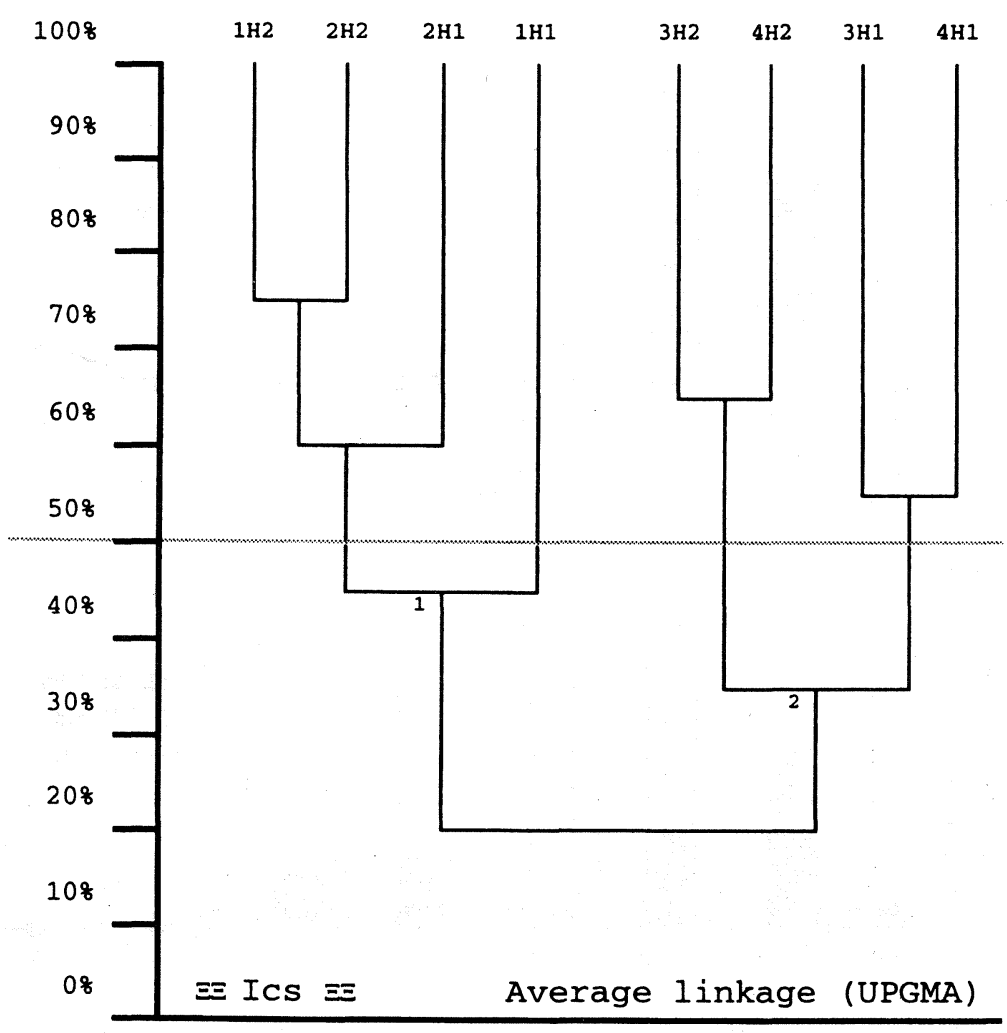

Fig. 1 Dendrogram of the similarity of studied habitats according to CZEKANOVSKI-SOERENSEN, calculated by average linkage method 
1) Zelotes

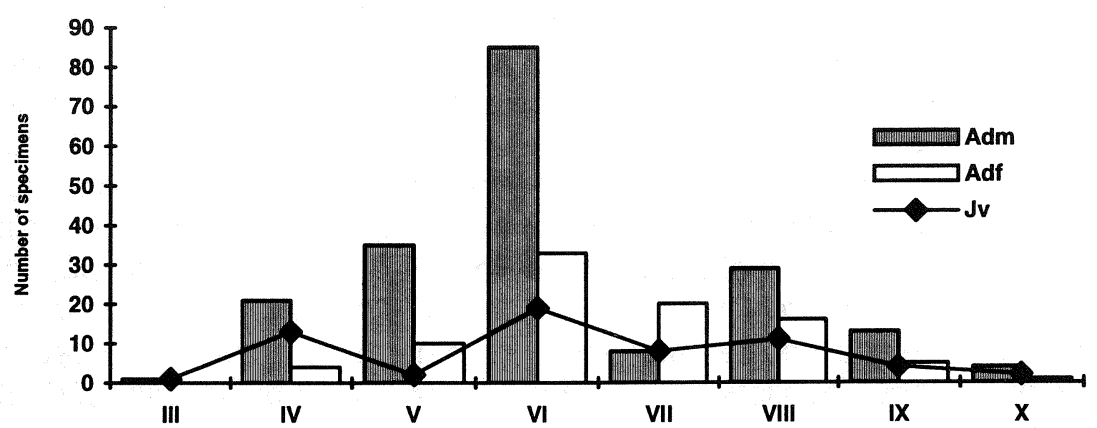

2) Haplodrassus

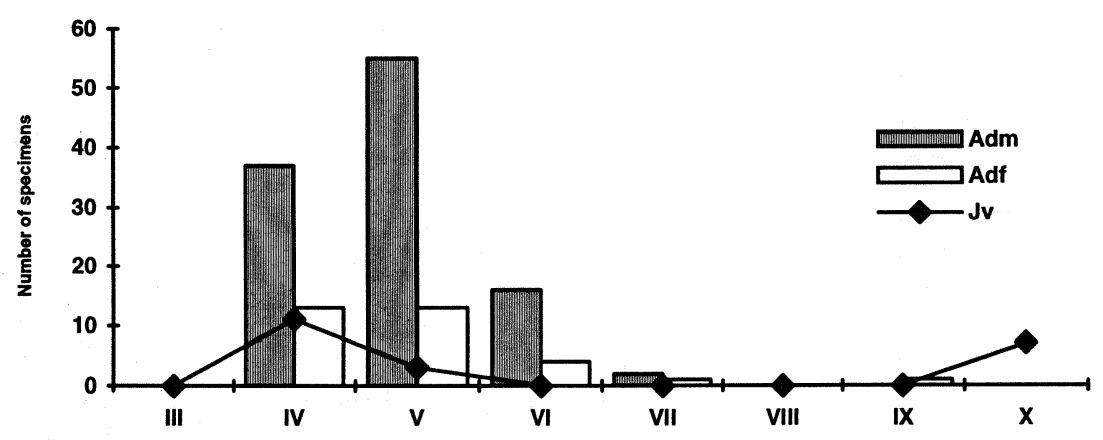

3) Micaria

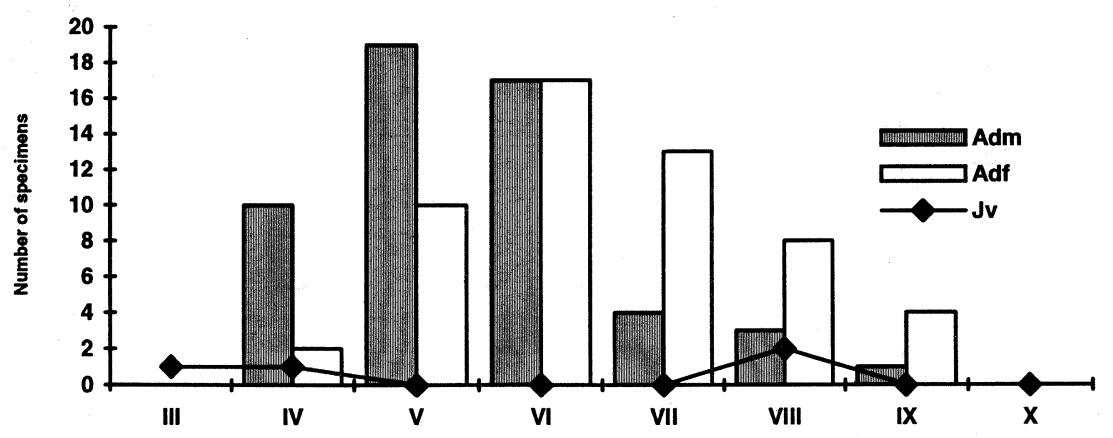

Fig. 2 Seasonal activity of the basic gnaphosid species (adm-adult males, Adf - adult females, Jv-juvenile specimens; $\mathrm{H} 1 \mathrm{~m}, \mathrm{H} 2 \mathrm{~m}$ - males in meadow and forest habitats, $\mathrm{H} 1 \mathrm{f}, \mathrm{H} 2 \mathrm{f}$ - females in meadow and forest habitats) 
4) Haplodrassus signifer

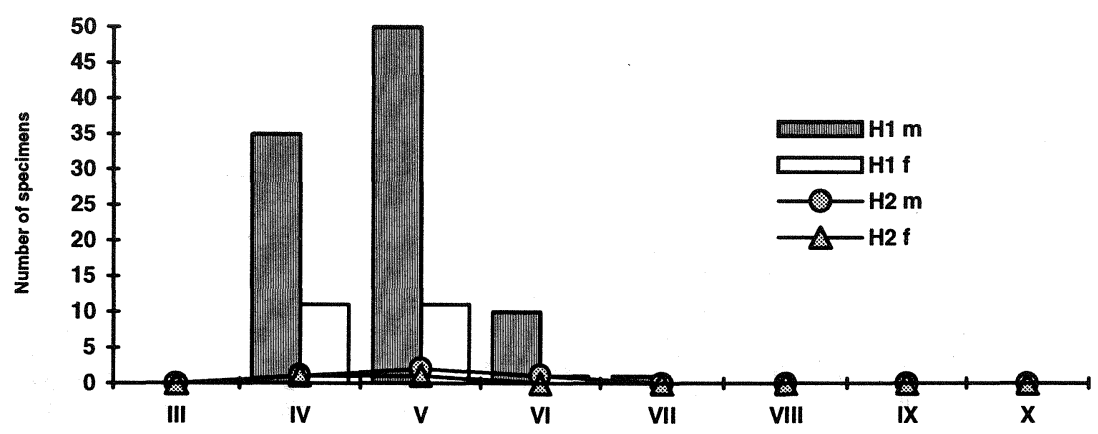

5) Zelotes pedestris

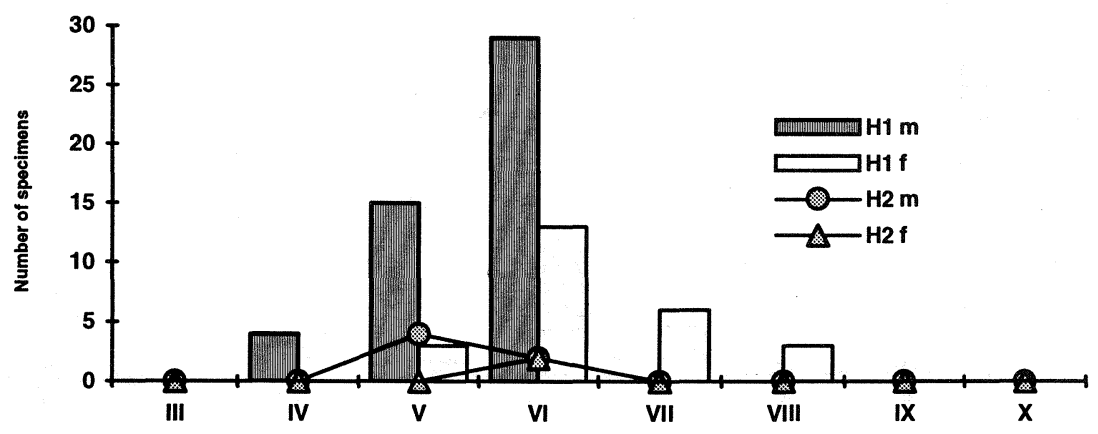

6) Zelotes praeficus

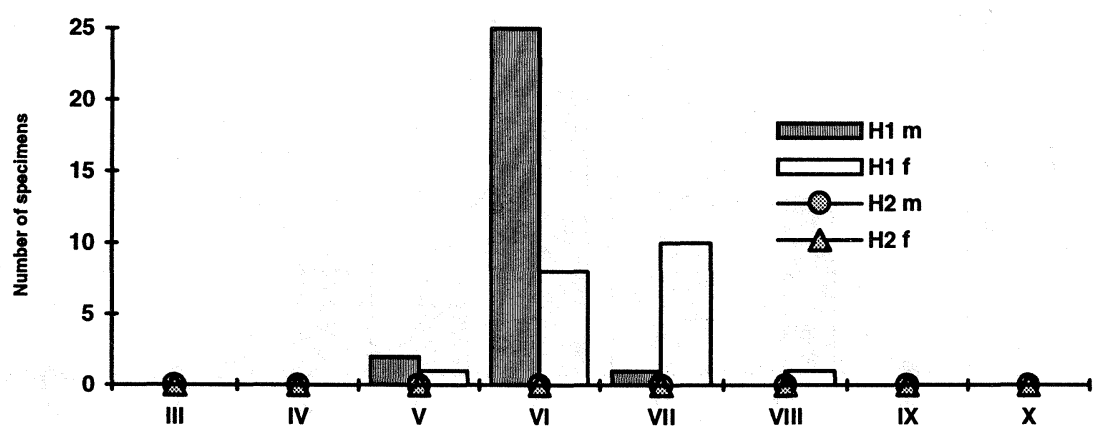

Fig. 2 cont. Seasonal activity of the basic gnaphosid species (adm-adult males, Adf - adult females, Jv - juvenile specimens; $\mathrm{H} 1 \mathrm{~m}, \mathrm{H} 2 \mathrm{~m}$ - males in meadowand forest habitats, $\mathrm{H} 1 \mathrm{f}, \mathrm{H} 2 \mathrm{f}$-females in meadow and forest habitats) 


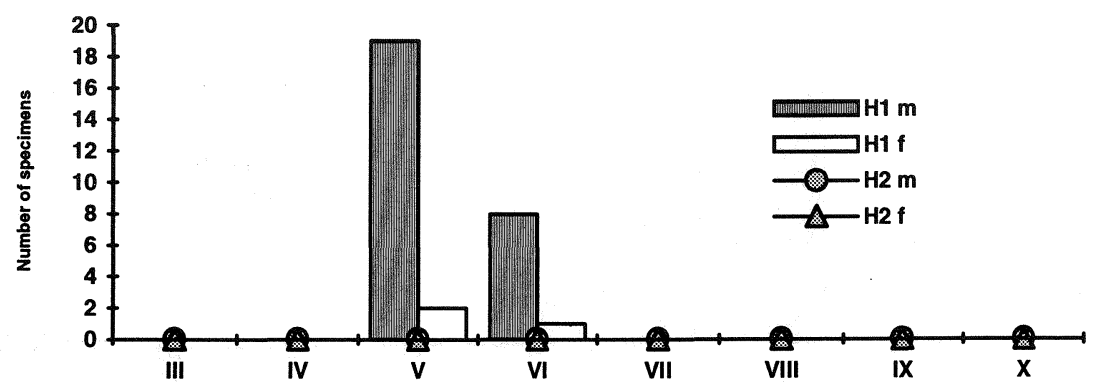

8) Callilepis schuszteri

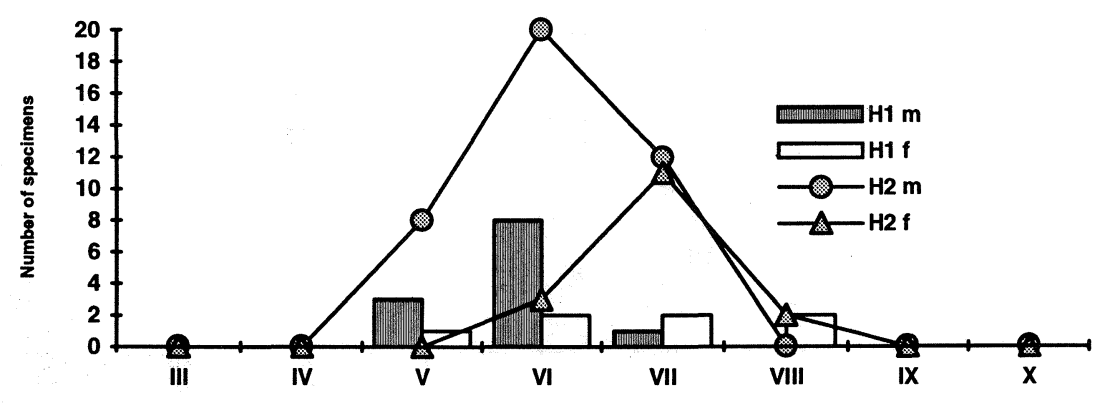

9) Micaria fulgens

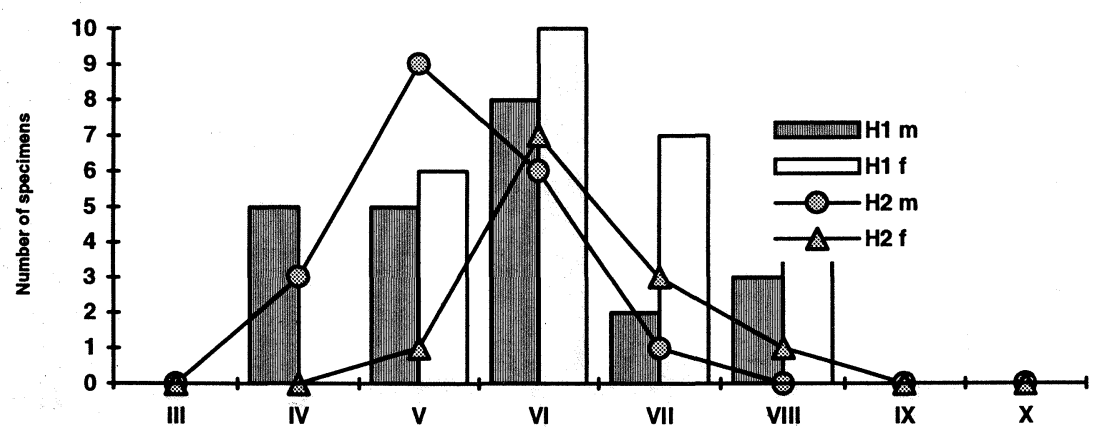

Fig. 2 cont. Seasonal activity of the basic gnaphosid species (adm-adult males, Adf - adult females, Jv - juvenile specimens; $\mathrm{H} 1 \mathrm{~m}, \mathrm{H} 2 \mathrm{~m}$ - males in meadowand forest habitats, $\mathrm{H} 1 \mathrm{f}, \mathrm{H} 2 \mathrm{f}$-females in meadow and forest habitats) 
10) Zelotes erebeus

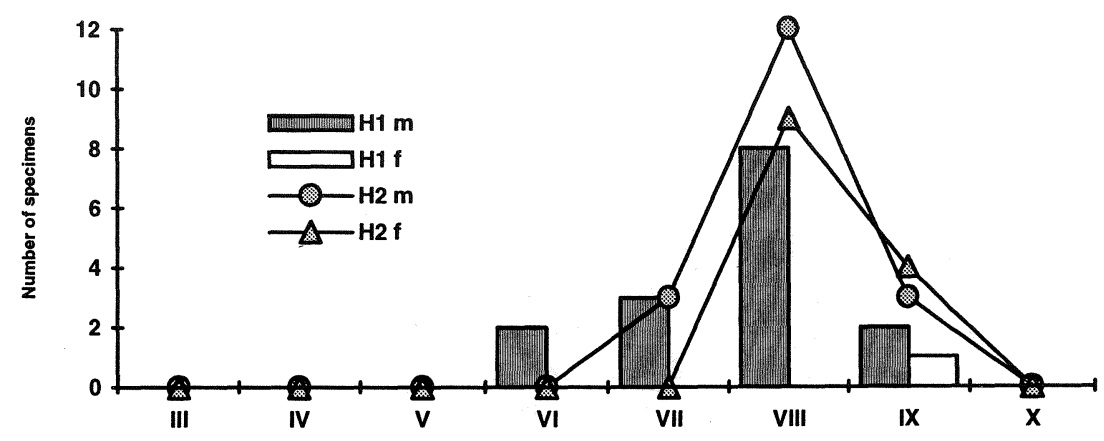

11) Zelotes exiguus

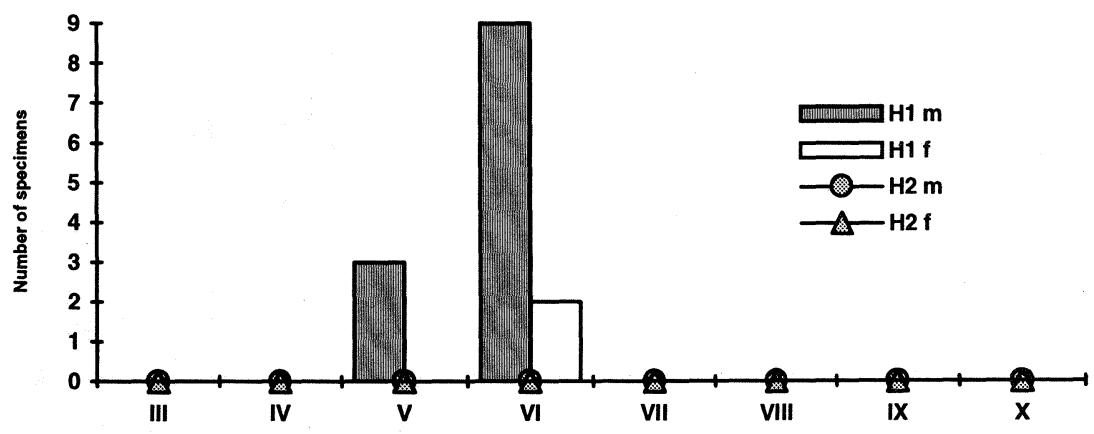

12) Zelotes electus

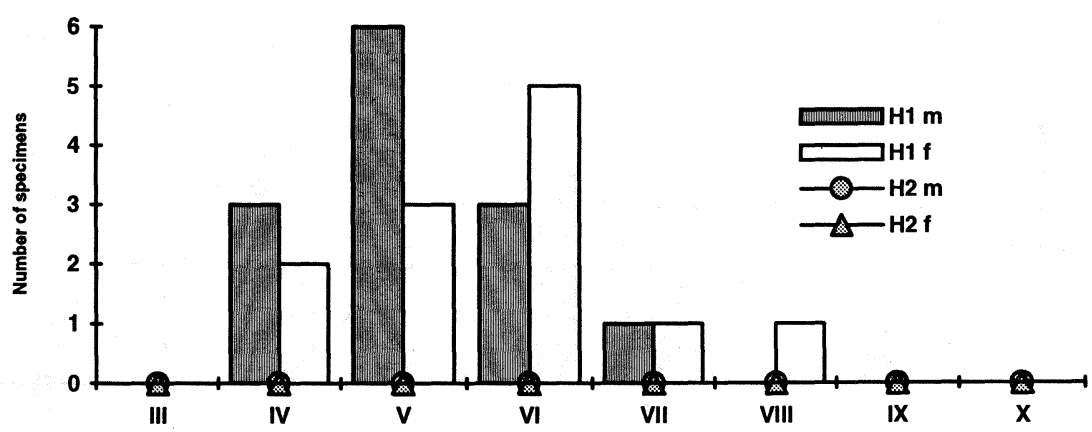

Fig. 2 cont. Seasonal activity of the basic gnaphosid species (adm -adult males, Adf - adult females, Jv - juvenile specimens; $\mathrm{H} 1 \mathrm{~m}, \mathrm{H} 2 \mathrm{~m}$ - males in meadowand forest habitats, $\mathrm{H} 1 \mathrm{f}, \mathrm{H} 2 \mathrm{f}$-females in meadow and forest habitats) 
13) Micaria pulicaria

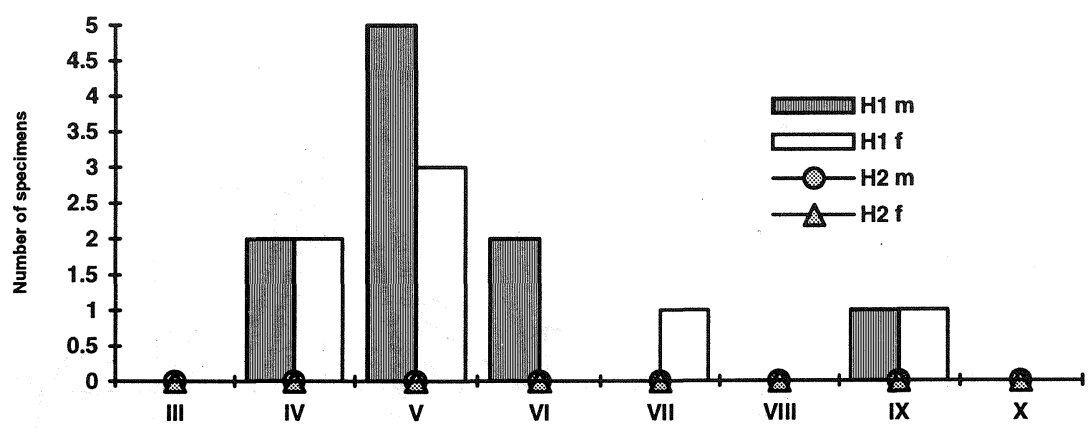

14) Zelotes hermani

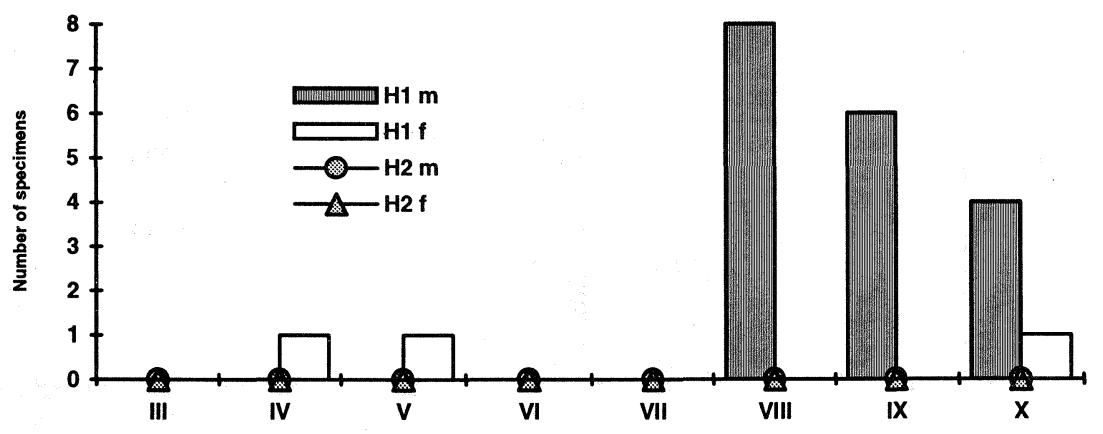

15) Haplodrassus silvestris

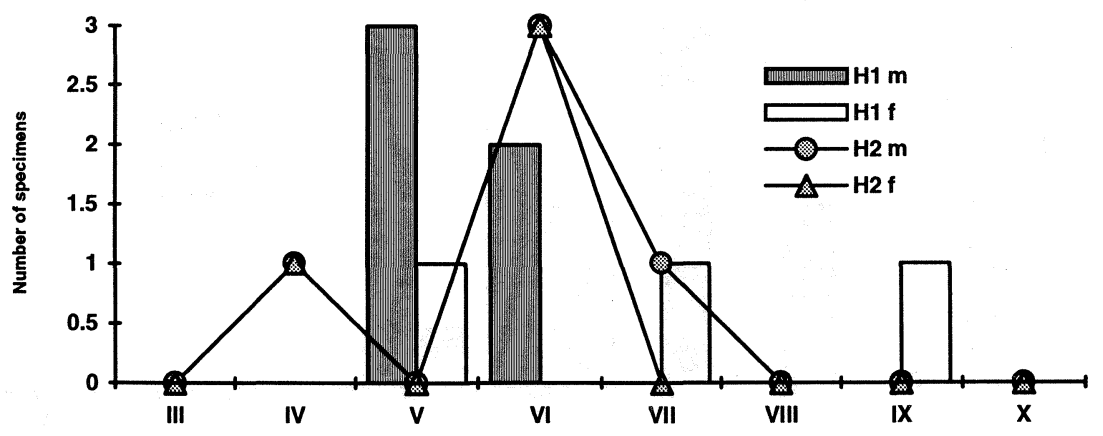

Fig. 2 cont. Seasonal activity of the basic gnaphosid species (adm - adult males, Adf - adult females, Jv - juvenile specimens; $\mathrm{H} 1 \mathrm{~m}, \mathrm{H} 2 \mathrm{~m}$ - males in meadowand forest habitats, $\mathrm{H} 1 \mathrm{f}, \mathrm{H} 2 \mathrm{f}$-females in meadow and forest habitats) 


\section{Phenological notes on the dominant species}

The data concerning seasonal activity of examined species (Fig. 2) are in accordance with the data for the gnaphosid spiders in Middle Europe given by GRIMM (1985). Some of the species ( $H$. signifer, $Z$. pedestris, Callilepis nocturna) in Middle Europe show an additional peak of activity during autumn (IX-X), while the data concerning Zemen gorge show an additional peak for $H$. signifer only (in X). The species $Z$. hermani is known only from the Balkan peninsula and Hungary; the data concerning the phenology are scanty. In Zemen gorge the species is active from IV till $X$ and the peak of abundance is during VIII. The data concerning the phenology of the genus Micaria in Middle Europe are not generalized and a comparison with the data from Zemen gorge is difficult. Micaria fulgens is active from IV till VIII with a peak in V-VI, while M. pulicaria is active from IV till IX with a peak in $\mathrm{V}$ (Fig. 2). The generalized data (Fig. 2) show that the genus Zelotes (III-X) and Haplodrassus (IV-X) have the longest activity. The juveniles appear during spring (III-IV) and disappear in autumn (X). The peak of abundance is during $\mathrm{V}-\mathrm{VI}$.

\section{CONCLUSIONS}

The established 23 species from family Gnaphosidae [in Zemen gorge (SW Bulgaria)] (33.8\% of their total number in Bulgaria) do not exhaust the species diversity of the region, because the research comprises only the habitats near the Struma river. The examined regions show a high faunistic similarity due to similar ecological conditions of the habitats. The ecological conditions in the region presuppose the domination of the meadow and forest-meadow species over the forest species. The males of the gnaphosid spiders are most abundant in spring and summer and disappear at the end of VIII, the females are most numerous after $V$ and can be found till the end of IX, while the juveniles can be found till the end of $X$. The species abundance reaches its peak during $\mathrm{V}-\mathrm{VI}$, then decreases, due to the draining of the region and the changing of the generations.

Acknowledgments: We thank Dr. R.F.FOELIX (Aarau) for linguistic improvement. 


\section{REFERENCES}

BLAGOEV, G.A. \& C.D.DELTSHEV (1989): [Biotopical distribution of wolf-spider (Araneae, Lycosidae) in the Zemen gorge, Southwestern Bulgaria.] - Ecology (bulg.) 22: 73-80

DELTSHEV, C.D. \& G.A.BLAGOEV (1992): A faunistic and zoogeographic analysis of spiders

(Araneae) in Zemen gorge (Southwestern Bulgaria). - Acta zoologica bulgarica 45: 26-35

GRIMM, U. (1985): Die Gnaphosidae Mitteleuropas (Arachnida, Araneae). Abh. Naturwiss. Ver. Hamburg (NF) 26: 318 pp.

TISHKOV, C. (1982): Climatic regions, subregions and districts. In: Geography of Bulgaria 1:472-477

WUNDERLICH, J. (1980): Revision der europäischen Arten der Gattung Micaria WESTRING 1851, mit Anmerkungen zu den übrigen paläarktischen Arten (Arachnida: Araneida: Gnaphosidae). - Zool. Beitr. 25(2): 233-341

Doz. Dr. Christo DELTSHEV \& Gergin BLAGOEV, Institute of Zoology, Bulgarian Academy of Sciences, blvd. Zar Osvoboditel 1, 1000-Sofia, BULGARIA 